\title{
Computer Games Designed for Disaster Prevention Learning
}

\author{
Chun-Hsiung Huang ${ }^{1}$, Szu-Ming Chung ${ }^{2}$ and $\mathrm{Mu}-\mathrm{Chiun} \mathrm{Hsu}^{3}$
}

\begin{abstract}
Disaster prevention learning is an important foundation to strengthen the land sliding disaster prevention and advocacy, to enhance people's knowledge, skills and attitude toward disaster prevention, and then to reinforce social force of prevention. This study uses Flash software tool to develop a disaster prevention game. This game includes three games with content related to land sliding prevention. They are tested by four dimensions, "willingness to learn” , "learning content" , "satisfaction", and "learning attitude". The results show that the pre- and post-test had significant difference. The tested participants felt significant difference before and after learning experience. After comparing the averages of four dimensions, all the post tested averages are all higher than the pre-tested ones. Thus it proves that this land sliding prevention game has certain learning effects.
\end{abstract}

Keywords: Disaster prevention learning • Digital game-based learning • Computer game design

\section{Introduction}

The terrain and environment are unique in Taiwan. The high mountains, hills, and terrace constitute about 69 percent of the island's land area. Taiwan's geology is in bad conditions. The heavy rains and earthquakes coupled with improper devel-

\footnotetext{
${ }^{1}$ Chun-Hsiung Huang $(\bowtie)$

Dept. of Information Management, National Yunlin University of Science and Technology, Yunlin, Taiwan

Dept. of Digital Content Design, Ling Tung University, Taichung, Taiwan e-mail: huangch@mail.ltu.edu.tw

2 Szu-Ming Chung

Dept. of Digital Content Design, Ling Tung University, Taichung, Taiwan

${ }^{3}$ Mu-Chiun Hsu

Dept. of Information Management, National Yunlin University of Science and Technology, Yunlin, Taiwan
} 
opment and utilization of mountain slopes, landslides and mudslides, and other natural disasters occur frequently. Especially landslides possess the characteristics of sudden, fast flow, violent impact, and great destruction. It is a serious threat to people's lives, safety, and property.

For the development of information technology and the popularization of personal computers and mobile devices, applications, computer games become a popular entertainment. They are not confined to the only feature of entertainment and can also be applied in education. Whether in school learning or workplace training, learners generally believe that the traditional way of learning is very boring. The game-based learning combined game situations and learning objectives are more attractive to today's learners. The game-based learning is to simulate real life situations and to guide learners to apply the knowledge imparted in the game. The learners would try to deal with real-life problems with learned knowledge in a simulated game. Game-based learning is interesting and fun, and also has something new to learn. Relatively, the learners feel it is easier to sense the fulfillment in the game world than in the real world.

This study created three related games of land sliding disaster prevention. These games are also tested by four dimensions of "willingness to learn" , "learning", "satisfaction", and "learning attitude" to verify the the learning effects. It is focused on methods and techniques in computer game design, and the learning effects of game based learning of land sliding disaster prevention learning.

\section{Related Research}

\subsection{Disaster Prevention Learning}

White [14] pointed out that the existence of natural disasters is closely related to the human reaction to it. It is the basic concept of knowing how to prevent the natural disasters. To avoid or reduce disasters, various advocacy and learning programs are basic to disaster prevention and rescue work. For the education is the most cost-effective investment of disaster prevention and rescue work. The priority of promoting the disaster prevention is to enhance public awareness of disasters, preparedness, and attitude and skills of disaster contingency.

The purpose of disaster prevention learning is to advance the public's knowledge of disaster, be prepared for it and to understand the importance of predisaster preparedness and emergency response, and training people to have good literacy of disaster prevention and strengthen the ability of disaster prevention and reduce losses. The level of knowledge and economic capacity of the people have a 
profound impact on learning the disaster prevention. The learning materials should reduce terminology learning, avoid advanced knowledge, and promote people's willingness to learn.

Kuo et al [5] pointed out that the difference between the characteristics of the community disaster prevention and traditional disaster prevention: 1 . Emphasis on the learning process rather than standardized learning outcomes; 2. Emphasis on great importance of people's cognitive knowledge and the change of affective side instead of skills transfer solely; 3 . The entire community plays the role of disaster prevention and rescue rather than relies only on the operation of a small number of core figures. The enthusiasm and reason of the public participation in disaster prevention are caused by a variety of reasons. In addition, with the rapid progression of information technology and network technology, by virtue of its advantage of its learning environment, online e-Learning provides learners with unlimited time and space. It has become the new emerged learning mode.

\subsection{Digital Game-Based Learning (DGBL)}

Recently digital game-based learning (Digital Game-based Learning, DGBL) prevailed in the field of teaching science and technology [2]. Aldrich [1] claimed that DGBL has already become a new model of digital learning. The reason why DGBL has gained much attention is mainly occupied in motivation of learning and solution of problems of traditional learning. Kuo [6] assumed that the teaching effectiveness by utilizing games mainly motivate the learning; construct social skills, and change attitude rather than to obtain knowledge acquisition mechanisms.

The DGBL intends to adopt educational format to promote interests in learning and to absorb the knowledge applied in the games. Scholars and experts also committed to explore the influential factors in DGBL of learning motivation and attainment. Bracey [3] found DGBL was very effective to motivate youth's learning. Squire [13] thought that the DGBL is a technical instruction by utilizing the characteristics of challenge and stimulation to arouse curiosity and momentum to learn. Csikszentmihalyi [4] assumed that the characteristic of inspiring curiosity by playing games is similar to immersion. There is no need of great extrinsic factor to motivate the learning; instead, the learning can be induced by the intrinsic motivation.

Furthermore, the competition mode implied in a digital game design helps stimulate learners to complete required learning tasks. Malone \& Lepper [8] stated that competition is extensively applied in motivation-learning strategy for work, study, and games. Playing games also offers many opportunities of practice to advance knowledge growth. It is a critical factor in the DGBL to improve memory [10]. Operating repeatedly in game playing implies the meaning of learning and 
thus to access the knowledge or skills from constant practice and systematic learning experience.

\subsection{Game Design}

Computer games as well as a movie styles are categorized $[9,11]$ as: action games (ACT), fighting game (FTG), simulation games (SIM), sports games (SPG), puzzle games (PUZ), strategy games (STA), role-playing games (RPG), and adventure game (AVG). To design a lively game can set up scoring system, level difficulty, physical/life-limiting, extra credits, blood injection, a pleasant surprise, and time extension [7].

The nature of game design must be conducted through strict planning and development, but also complied with certain formatting process. Rollings \& Morris [12] proposed three stages of game design: concept, structure, and design stage. The concept stage constitutes inspiration, comprehension, resonance, and polymerization procedures. The structural stage explores dramatic mode, including five elements of style, plot, character, setting, and theme. The design stage consists the actual visual planning, the role rendering, scene design, sound settings, and programming.

\section{Results and Discussions}

\subsection{Game Development, Problems, and Solutions}

Whether on a mathematical way to describe the points and curves vector graphic or bitmap file, the synthesis of the pixel can be applied on Flash games. Obtaining the best balance between the efficiency of game and performance of visual interface is the focus of consideration in the game design. The drawing tools of Flash are mainly vector graphic which possess a small file size, great flexibility, the graphics scaling unaffected the quality of its graphics. However, a complex vector graphics will drag on gaming performance.

In addition to visual effects and tactile feel of controlling the role, soundscape is also critical to game design. The soundscape may include background music and sound effects. Flash records sound in two ways, one is to input sound directly in the frame, the other is programmed and controlled through ActionScript syntax. Each has its advantages and disadvantages. 
For a game developer, understanding the Cartesian coordinate system is a required basic knowledge. Object positioning and moving must be handled through configuration of the coordinate system. In Flash, the original point of the coordinate system is defined in the upper left corner of the video screen. The x-axis value is the greater while moving toward the right side. And, the $y$-axis value is greater while moving downward to the bottom.

The applications of Tile-based worlds in game design allow the implementation to be more efficient. All image material can be reused, and can easily use the programming codes to construct the entire game screen. The tile-based world concept of a game screen design is to connect each tile seamlessly. It is as a 2 dimensional plan constructed by two or four consecutive patterns.

The collision is a physics term. Two separate bodies, in the same space, share one or more points. While picking up a treasure or encountering with an enemy in the game, the player controls the character to make realistic actions and reactions. This needs to deal with collision detection. In other words, the game must have a collision, and the collision must be detected, in order to make the character to react. In general, common collisions happen between line and line, circle and line, and rectangular and rectangular collision and cross.

The applications of artificial intelligence allow the character to find the best path and make the logical judgments with actions through the programming. It can be both fun and interesting. It also allows the player unable to estimate the enemy's next action and behavior, which increases the difficulty of the game. The player will not like to follow the same path or make the same moves in a game. Artificial intelligence is the critical part to decide the fun and interesting of a game.

The high score ranking is the list of the best scores. It creates the competition among players. It is the tool to compare and to compete. It can also increase the repetition of the playability of the game. In Flash, it can not only take advantage of a variable or an array to store the high score ranking, but also through the network and remote database links to add, modify, delete, search and browse information.

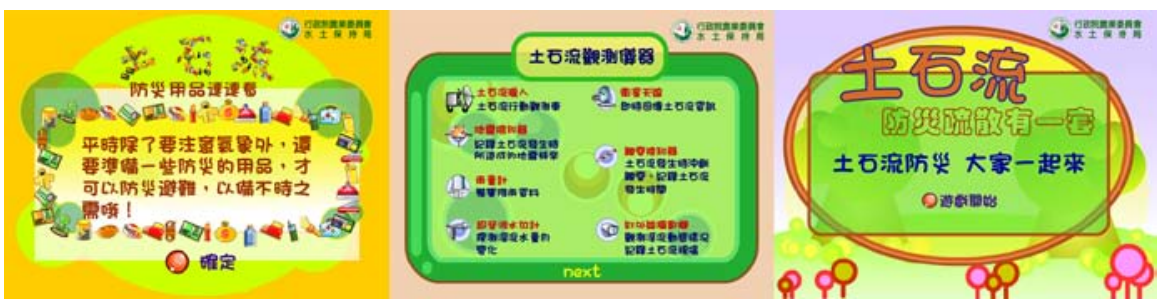

Fig. 1 Game playing interface. 


\subsection{Research Experiments and Results}

\subsubsection{Experiment Design}

This game design includes three games: “emergency supplies matching” , "landslide hunter", and "A good evacuation plan for landslide disaster" . The purpose of this game design is for the public to remember emergency/prevention supplies of landslide disaster, to know landslide observation tools and instruments and to further achieve a landslide warning/prevention advocacy.

To verify the effectiveness of the game design, this study design an experiment to test four dimensions of "willingness to learn" , "learning content" , "satisfaction" and "learning attitude" of the disaster prevention games. This study involved 61 participants of sophomores. They took the pre-test before playing the games and the post-test after play three games in order. Comparisons are made between these two tests.

\subsubsection{Credibility and Validity Analyses}

Prior to the experiments, three experts with relevant experience help to construct the pre- and post-test questionnaire. Therefore, the questionnaire has content validity. Reliability is a measure of the consistency of the questionnaire. This study uses Cronbach's $\alpha$ test the results. The findings are in Table 1. The value of Cronbach's $\alpha$ is between $0.733-0.918$. The values of four dimensions are greater than 0.7. It has considerable high credibility.

Table 1 Pre- and post-test of four dimensions and values of Cronbach's $\alpha$

\begin{tabular}{|c|c|c|c|}
\hline Dimensions & Pre-test & Post-test & Remarks \\
\hline Willingness to learn & .742 & .733 & \\
\hline Learning content & .859 & .841 & \\
\hline Satisfaction & .903 & .898 & \\
\hline Learning attitude & .886 & .918 & \\
\hline
\end{tabular}

\subsubsection{Learning Attainment of Landslide Disaster Prevention}

This study sets up four dimensions of the "willingness to learn” , “learning content" , "satisfaction" and "learning attitude" to be verified. T test data are listed in Table 2. Through pre- and post-test paired $\mathrm{T}$ test data can be found in Table 2. The averages of pre- and post-test of "willingness to learning” are be- 
tween 2.66 and 3.49; “learning content” are between 2.55 and 3.69; “satisfaction" are between 2.48 and 3.73; "learning attitude" are between 2.70 and 3.94. In the paired $T$ test, the results were significant differences $(p=.000<.05)$. Overall, participants' prior and after learning experience is significantly different. Comparing the averages of 4 dimensions, the post-test averages are all greater than the pretest. Therefore, the learning effectiveness is verified in these landslide disaster prevention games. Among four dimensions, the post-test average of satisfaction increases the most (1.25). Through game playing, the learners feel significant difference in satisfaction. In dimension of “learning attitude" , the post-test average increases greater as 1.24 . It confirmed this approach to learning will advance learners' recognition for learning and inspire the positive attitude. The posttest average of "learning content" becomes greater as 1.13. It confirmed that game-based learning is more effective than traditional publicity and teaching. The post-test average of “willingness to learn” though is not so great as low as 0.83 , the "willingness to learn" is under the condition of game-based learning, which is compared to the traditional learning, and learners are more willing to learn. Overall, through statically experiment to verify the learning effectiveness, the results are significantly different.

Table $2 \mathrm{~T}$ test data

\begin{tabular}{|c|c|c|c|c|}
\hline Dimensions & Pre-test mean & Post-test mean & T value & Significance (P value) \\
\hline Willingness to learn & 2.6598 & 3.4877 & -6.332 & .000 \\
\hline Learning content & 2.5533 & 3.6926 & -7.956 & .000 \\
\hline Satisfaction & 2.4754 & 3.7295 & -9.230 & .000 \\
\hline Learning attitude & 2.7016 & 3.9377 & -8.220 & .000 \\
\hline
\end{tabular}

(Judgment value $\mathrm{p}<0.05$ )

\section{Conclusion}

This study adopts Flash to develop landslide disaster prevention games, action games. To design computer games, the applications not only include making good use of the scoreboard, levels, life-limit of the characters, extra credits, game time length control method to increase the playability of the game, but also understanding the graphics, soundscape, coordinate systems, tile-based worlds, collision detection, artificial intelligence, and other areas of knowledge in order to design a rich and vivid, interesting and attractive game. Games produced by Flash can be downloaded from the Internet to spread, which can accumulate the variety of learning resources related to landslide disaster prevention. This study also verified positive learning effectiveness through pre- and post-testing of four dimensions of 
“willingness to learn” , "learning content", "satisfaction” and "learning attitude" . This experiment confirmed computer game-based learning has positive impact on learners for landslide disaster preparedness and prevention.

During the development of games, the authors also found that Flash is very suitable for other types of game development with a complex plot and multilayered structure, such as adventure games and computer role-playing game. Combining different types of games and different levels of skills and applying to different learning are possible in the future development. The authors recommend more research applied in similar applications and tested their results and learning effectiveness by more dimensions to explore extensively in many possible design of game-based learning.

\section{References}

1. Aldrich, C. (2004). Simulations and the future of learning. New York: Pfeiffer.

2. Becker, K. (2007). Digital game-based learning once removed: Teaching teachers. British Journal of Educational Technology, 38(3), 478-488.

3. Bracey, G.W.(1992). The bright future of integrated learning systems. Educational Technology, 32(9), 60-62.

4. Csikszentmihalyi, M. \& LeFevre, J.(1989). Optimal experience in work and leisure. Journal of Personality and Social Psychology, 56(5), 815-822.

5. Kuo, Chun-Chin, Juang, Han-Hwa, \& Kang, Liang-Yu (2011). A study on factors affecting community disaster prevention learning. Journal of National Taichung University, Humanities \& Arts, 25(1), 99-123.

6. Kuo, Mei-Jen (2007). How does an online game based learning environment promote students' intrinsic motivation for learning natural science and how does it affect their learning outcomes? Proceedings of the First IEEE International Workshop on Digital Game and Intelligent Toy Enhances Learning, 135-143.

7. Makar, J. \& Winiarczyk, B. (2004). Macromedia Flash Mx 2004 Game Design Demystified. San Francisco, California: Macromedia Press.

8. Malone, T. W. \& Lepper, M. R. (1987). Making learning fun: A taxonomy of intrinsic motivations for learning. Aptitude, Learning, and Instruction, 3, 223-253.

9. Meigs, T. (2003). Ultimate Game Design: Building Game Worlds. New York, New York: McGraw-Hill Osborne Media.

10. Péladeau, N., Forget, J., \& Gagné, F. (2003). Effect of paced and unpaced practice on skill application and retention: How much is enough? American Educational Research Journal, 40(3), 769-801.

11. Rollings, A. \& Adams, E. (2003). Andrew Rollings and Ernest Adams on Game Design. San Francisco, California: New Riders.

12. Rollings, A. \& Morris, D. (2003). Game Architecture and Design: A New Edition. San Francisco, California: New Riders

13. Squire, K., Jenkins, H., Holland, W., Miller, H., O'Driscoll, A., Tan, K. P. \& Todd, K. (2003). Design principles of next-generation digital gaming for education. Educational Technology, 43(5), 17-23.

14. White, G. F. (1974). Natural hazards research: concepts, methods, and policy implications. Natural Hazards: Local, National, Global. New York: Oxford University Press. 